\title{
PENERAPAN METODEEXPECTED SHORTFALLPADA PENGUKURAN RISIKO INVESTASI SAHAM DENGAN VOLATILITAS MODEL GARCH
}

\author{
Nurul Fitria Rizani ${ }^{1}$, Mustafid ${ }^{2}$, Suparti $^{3}$ \\ 1,2,3 Departemen Statistika FSM Universitas Diponegoro \\ Mustafid55@gmail.com
}

\begin{abstract}
One of the methods that can be used to measure stock investment risk is Expected Shortfall (ES). ES is an expectation of risk size which value is greater than Value at Risk (VaR), ES has characteristics of sub-additive and convex. The Generalized Autoregressive Conditional Heteroskedasticity (GARCH) model is used to model stock data that has high volatility. Calculating ES is done with data that shows deviations from normality using Cornish-Fisher's expansion. This researchapplies the ES at the closing stock price of PT Astra International Tbk. (ASII), PT Bank Negara Indonesia (Persero) Tbk. (BBNI), and PT Indocement Tunggal Prakarsa Tbk. (INTP) for the period of 11 February 2013 - 31 March 2019. Based on the volatility of GARCH $(1,1)$ analysis, we find ES calculation for each stock by $95 \%$ level confidence. The ES for ASII shares is $4.1 \%$, greater than the VaR value which isonly $2.64 \%$. The ES for BBNI shares is $4.38 \%$, greater than it's VaR value which is only $2,86 \%$. The ES for INTP shares is $6.22 \%$, which is also greater than it's VaR value which is only3,99\%. The greather of VaR then Thegreather of ES obtained.
\end{abstract}

Keywords: Expected Shortfall, Value at Risk, GARCH

\section{PENDAHULUAN}

Saham merupakan salah satu aset keuangan yang dipilih investor dengan mengharapkan return sebesar-besarnya dengan risiko tertentu dalam berinvestasi. Semakin besar return yang diharapkan oleh investor maka risiko yang dihadapi investor juga semakin besar. Salah satu bentuk pendugaan risiko yang cukup popular dan paling sering digunakan dalam analisis risiko keuangan adalah Value at Risk (VaR). VaR memiliki kelemahan hanya mengukur persentil dari distribusi keuntungan atau kerugian tanpa memperhatikan setiap kerugian yang melebihi tingkat VaR. Untuk mengatasi kelemahan tersebut, diperlukan Conditional Value at Risk (CVaR) atau Expected Shortfall (ES). ES didefinisikan sebagai ekspektasi ukuran risiko yang nilainya lebbiih besar dari VaR, serta memiliki sifat subadditive dan sifat convex.ES merupakan dugaan risiko yang dapat bekerja pada data yang berdistribusi normal maupun tidak normal.

Penelitian ini menggunakan data harga penutupan saham (closing price) dengan periode waktu harian. Saham yang digunakan adalah PT Astra International Tbk. (ASII), PT Bank Negara Indonesia (Persero) Tbk. (BBNI), dan PT Indocement Tunggal Prakarsa Tbk. (INTP). Data harga penutupan saham dimulai periode 11 Februari 2013 sampai dengan 31 Maret 2019. Tujuan penelitian ini yaitu menerapkan Expected Shortfall pada model volatilitas ARIMA-GARCH untuk menentukan tingkat risiko. 


\section{TINJAUAN PUSTAKA \\ 2.1 Investasi}

Investasi adalah komitmen atas sejumlah dana atau sumber daya lainnya yang dilakukan pada saati ini, dengan tujuan memperoleh keuntungan di masa yang akan datang (Tandelilin, 2010). Investasi biasanya digolongkan menjadi dua yaitu, aset riil dan aset keuangan. Aset keuangan dapat diwakili oleh selembar kertas sebagai bukti klaim kepada pihak penerbit, seperti saham.

\subsection{Saham}

Saham merupakan tanda penyertaan atau pemilikan seseorang atau badan dalam satu perusahaan atau perseroan terbatas (Darmadji dan Fakhruddin, 2001). Keuntungan yang diperoleh investor dengan membeli atau memiliki saham yaitu, deviden dan capital gain.

\subsection{Return}

Menurut Ghozali (2007), return merupakan pendapatan yang akan diterima jika investor menginvestasikan uang pada suatu asset riil (property, tanah) atau asset keuangan (saham, obligasi). Return saham dapat dihitung harian, mingguan, bulanan, dan tahunan. Semakin pendek periodenya maka perhitungan return sebaiknya menggunakan model geometri yang dapat dihitung dengan rumus berikut:

$$
R_{t}=\ln \frac{P_{t}}{P_{t-1}}
$$

dengan $R_{t}$ adalah nilai return pada waktu ke- $t, P_{t}$ adalah harga saham periode $t$, dan $P_{t}$ adalah harga saham peride sebelumnya.

\subsection{Analisis Runtun Waktu}

Data runtun waktu $\left(X_{t}\right)$ adalah jenis data yang dikumpulkan menurut urutan waktu dalam suatu rentang tertentu. Dasar pemikiran runtun waktu adalah pengamatan sekarang $\left(X_{t}\right)$ tergantung pada satu atau beberapa pengamatan sebelumnya $\left(X_{t-k}\right)$. Tujuan analisis runtun waktu adalah untuk memahami dan menjelaskan mekanisme tertentu, meramalkan suatu nilai di masa akan datang, dan mengoptimalkan sistem kendali (Makridakis et al.,1999).

\subsubsection{Model Autoregressive (AR)}

$X_{t}=\phi_{1} X_{t-1}+\phi_{2} X_{t-2}+\cdots+\phi_{p} X_{t-p}+a_{t}$

dengan $X_{t}$ adalah data pada runtun waktu ke- $t, \phi_{p}$ adalah parameter dari model autoregressive, dan $a_{t}$ adalah nilai residual pada waktu ke- $t$.

\subsubsection{Model Moving Average (MA)}

$$
X_{t}=a_{t}-\theta_{1} a_{t-1}-\theta_{2} a_{t-2}-\cdots-\theta_{q} a_{t-q}
$$


dengan $X_{t}$ adalah data pada runtun waktu ke- $t, \theta_{q}$ adalah parameter dari model moving average, dan $a_{t}$ adalah nilai residual pada waktu ke- $t$.

\subsubsection{Model Autoregressive Moving Average (ARMA)}

$$
\begin{aligned}
X_{t}= & \phi_{1} X_{t-1}+\phi_{2} X_{t-2}+\cdots+\phi_{p} X_{t-p}+a_{t}-\theta_{1} a_{t-1}-\theta_{2} a_{t-2}-\cdots- \\
& \theta_{q} a_{t-q}
\end{aligned}
$$

\subsubsection{Model Autoregressive Integrated Moving Average (ARIMA)}

$\phi_{p}(B)(1-B)^{d} Z_{t}=\theta_{0}+\theta_{q}(B) a_{t}$

dengan, $\phi_{p}(B)=\left(1-\phi_{1} B-\cdots-\phi_{p} B^{p}\right), \theta_{q}(B)=\left(1-\theta_{1} B-\cdots-\theta_{q} B^{q}\right)$

\subsection{Model Autoregresive Conditional Heteroscedasticity (ARCH) dan Generalized Autoregresive Conditional Heteroscedasticity (GARCH)}

ARCH adalah salah satu model ekonometrika yang diperkenalkan oleh Engle (1982) dan kemudian dikembangkan oleh Bollerslev (1986) menjadi model GARCH. Pada perkembangannya model ARCH-GARCH menjadi andalan untuk analisis runtun waktu pada pasar modal. Bentuk umum model $\mathrm{ARCH}(\mathrm{m})$ sebagai berikut (Tsay, 2005):

$$
\begin{aligned}
a_{t} & =\sigma_{t} \epsilon_{t} \\
\sigma_{t}^{2} & =\alpha_{0}+\alpha_{1} a_{t-1}^{2}+\alpha_{2} a_{t-2}^{2}+\cdots+\alpha_{m} a_{t-m}^{2}
\end{aligned}
$$

dengan :

$\alpha_{0} \quad$ :komponenkonstanta

$\alpha_{m} \quad$ : parameter $\mathrm{ARCH}$

$\alpha_{t-m}^{2}:$ residual kuadrat pada waktu t-m

$\sigma_{t}^{2} \quad$ :variansi residual pada saat

dengan $\epsilon_{t}$ merupakan variabel acak yang independen dan identik dengan mean 0 dan varian 1, dalam model ARCH parameter-parameternya harus memenuhi $\alpha_{0}>$ $0, \alpha_{i} \geq 0$, dengan $i=1,2, \ldots, m$. Sedangkan bentuk umum model GARCH $(\mathrm{m}, \mathrm{s})$ sebagai berikut:

$$
\begin{aligned}
X_{t} & =\mu_{t}+a_{t} \\
a_{t} & =\sigma_{t} \epsilon_{t} \\
\sigma_{t}^{2} & =\alpha_{0}+\sum_{i=1}^{m} \alpha_{i} a_{t-i}^{2}+\sum_{j=1}^{s} \beta_{j} \sigma_{t-j}^{2}
\end{aligned}
$$

dengan $\epsilon_{t}$ merupakan variabel acak yang independen dan identik dengan mean 0 dan varian $1, \alpha_{0}>0, \alpha_{i} \geq 0, \beta_{j} \geq 0$, dan $\sum_{i=1}^{m} \sum_{j=1}^{s}\left(\alpha_{i}+\beta_{j}\right)<1 . \beta_{j}$ merupakan parameter GARCH dan $\sigma_{t-j}^{2}$ merupakan kuadrat dari variansi residual pada waktu $t-j$ (Tsay, 2005).

\subsection{Value at Risk}


Value at Risk (VaR) merupakan alat ukur yang dapat menghitung besarnya kerugian terburuk yang dapat terjadi dengan mengetahui posisi aset, tingkat kepercayaan akan terjadinya risiko, dan jangka waktu penempatan aset (Jorion, 2007). Dari definisi diatas, VaR merupakan kerugian terburuk dari suatu aset dengan jangka waktu tertentu pada suatu tingkat kepercayaan tertentu. VaR mengukur volatilitas dari aset perusahaan, sehingga semakin besar volatilitas maka semakin besar kemungkinan kerugian. Artzner et al. (1999) mendefinisikan bahwa VaR dengan tingkat kepercayaan $100(1-\alpha) \%$ pada waktu ke- $t$ adalah sebagai berikut:

$$
\begin{aligned}
& \operatorname{VaR}_{\alpha}^{t}(X)=-i n f\{x \mid P(X \leq x)>\alpha\} \\
& \operatorname{VaR}_{\alpha}^{t}(X)=-\hat{\mu}_{t}-\hat{\sigma}_{t} F^{-1}(\alpha)
\end{aligned}
$$

dengan:

$V_{a}^{t} R_{\alpha}$ : Nilai Value at Risk pada waktu t dengan tingkat kepercayaan $\alpha$

$\hat{\mu}_{t} \quad$ : Taksiran rata-rata dari return pada waktu $t$

$F^{-1}(\alpha)$ : Kuantil- $\alpha$ dari distribusi normal

$\hat{\sigma}_{t} \quad$ : Varian dari return pada waku $t$

\subsection{Expected Shortfall}

Expected Shortfall merupakan suatu ukuran risiko yang memperhitungkan kerugian melebihi tingkat Value atRisk (VaR). Expected Shortfall digunakan sebagai alternatif dalam pengukuran risiko yang berfungsi mengurangi masalah yang terjadi pada VaR (Rockafellar dan Uryasev, 2000). Expected Shortfall (ES) memiliki kelebihan antara lain merupakan ukuran risiko yang koheren serta memiliki sifat convex dan sub-additive.

Artzner et al.(1997) telah mengusulkan ES sebagai metode untuk mengatasi masalah yang ada pada VaR. Pada distribusi kontinu dengan tingkat kepercayaan $100(1-\alpha)$ dan pada kurun waktu $t$, ES merupakan ekspektasi dari kerugian bersyarat melebihi VaR.Secara teknis Yamai dan Yoshiba (2002) mendefinisikan ES, dengan $X$ merupakan variabel acak keuntungan atau kerugian dari portofolio dan $\operatorname{VaR}_{\alpha}(X)$ dengan tingkat kepercayaan $100(1-\alpha) \%$, maka ES dapat dirumuskan sebagai berikut:

$$
E S_{\alpha}^{t}(X)=E\left[-X \mid-X \geq \operatorname{VaR}_{\alpha}(X)\right]
$$

dimana nilai Expected Shortfall $E S_{\alpha}^{t}$ merupakan ukuran risiko pada waktu $t$ dengan tingkat kepercayaan $\alpha$, yang merupakan minus expected dari $X$ dengan $X$ lebih atau sama dari nilai Value at Risk.

$$
\begin{gathered}
E S_{\alpha}^{t}(X)=-\frac{1}{\alpha} \int_{-\infty}^{-V a R_{\alpha}} t f(x) d t \\
E S_{\alpha}^{t}(X)=-\hat{\mu}_{t}+\hat{\sigma}_{t} \frac{\phi\left(F^{-1}(\alpha)\right)}{\alpha}
\end{gathered}
$$


dengan $\phi$ merupakan fungsi densitas dari normal standar.

Data pada bidang keuangan sering menunjukkan sifat kemencengan dan keruncingan berlebih yang menunjukkan penyimpangan dari normalitas. kemencengan dan kelebihan keruncingan dengan menggunakan ekspansi CornishFisher untuk menghitung $\mathrm{VaR}$ dan ES diperoleh rumusan sebagai berikut (Situngkir, 2006):

$$
\begin{aligned}
\operatorname{VaR}_{\alpha}^{t}(x)= & -\hat{\mu}_{t}-\hat{\sigma}_{t} F_{C F}^{-1}(\alpha) \\
F_{C F}^{-1}(\alpha)= & \phi^{-1}(\alpha)+\frac{S}{6}\left(\left[\phi^{-1}(\alpha)\right]^{2}-1\right)+\frac{K-3}{24}\left(\left[\phi^{-1}(\alpha)\right]^{3}-3 \phi^{-1}(\alpha)\right) \\
& -\frac{S^{2}}{36}\left(2\left[\phi^{-1}(\alpha)\right]^{3}-5 \phi^{-1}(\alpha)\right)
\end{aligned}
$$

Sehingga ES persamaan (13) dapat dihitung sebagai berikut:

$$
E S_{\alpha}^{t}(X)=-\hat{\mu}_{t}+\frac{\widehat{\sigma}_{t}}{\alpha \sqrt{2 \pi}} e^{-\frac{\left(F_{C F}^{-1}(\alpha)\right)^{2}}{2}}
$$

dengan:

$E S_{\alpha}^{t} \quad$ : Nilai Expected Shortfall pada waktu $t$ dengan tingkat kepercayaan $\alpha$

$\hat{\mu}_{t} \quad$ : Taksiran rata-rata dari return pada waktu $t$

$F^{-1}(\alpha)$ : Kuantil- $\alpha$ dari distribusi normal

$\hat{\sigma}_{t} \quad$ : Varian dari return pada waku $t$

\section{METODOLOGI PENELITIAN}

\subsection{Sumber dan Variabel Penelitian}

Data yang digunakan pada penelitian ini adalah data sekunder harga penutupan saham (closing price) dengan periode waktu harian mulai periode 11 Februari 2013 sampai dengan 31 Maret 2019. Data harga penutupan saham harian diperoleh dari situs www.finance.yahoo.com. Variabel yang digunakan pada penelitian ini berupa nilai return saham harian pada PT Astra International Tbk. (ASII), PT Bank Negara Indonesia (Persero) Tbk. (BBNI), dan PT Indocement Tunggal Prakarsa Tbk. (INTP).

\subsection{Tahapan Analisis Data}

1. Menghitung nilai return saham dari masing-masing harga saham

2. Menganalisis masing-masing nilai return saham secara deskriptif

3. Melakukan uji stasioneritas data dalam varian menggunakan uji Box-Cox dan uji stasioneritas data dalam mean menggunakan plot time series dan uji Augmented Dickey-Fuller.

4. Setalah data dinyatakan stasioneritas dalam varian maupun mean maka selanjutnya membuat plot ACF dan PACF dari masing-masing return saham untuk menentukan order dan mendapatkan model sementara.

5. Melakukan estimasi parameter model dari masing-masing return saham. 
6. Melakukan pengujian signifikansi parameter model dari masing-masing return saham.

7. Melakukan uji asumsi yang terdiri dari uji independensi residual, uji normalitas residual, dan uji homoskedastisitas residual.

8. Pemilihan model ARIMA terbaik yang memiliki nilai AIC terkecil.

9. Melakukan identifikasi model ARIMA-GARCH serta melakukan pengujian signifikansi parameter dan normalitas residual dari model ARIMA-GARCH.

10. Menghitung nilai Value at Risk (VaR).

11. Menghitung nilai Expected Shortfall.

12. Interpretasi nilai Value at Risk (VaR) dan Expected Shortfall.

13. Kesimpulan

4. HASIL DAN PEMBAHASAN

\subsection{Karakteristik Return Saham}

Data yang digunakan adalah data sekunder harga penutupan saham harian dariadalah PT Astra International Tbk. (ASII), PT Bank Negara Indonesia (Persero) Tbk. (BBNI), dan PT Indocement Tunggal Prakarsa Tbk. (INTP) mulai 11 Februari 2013sampai dengan 8 Februari 2019. Berikut merupakan plot runtun waktu daripenutupan harga saham ASII, BBNI, dan INTP yang terdapat pada Gambar 1.
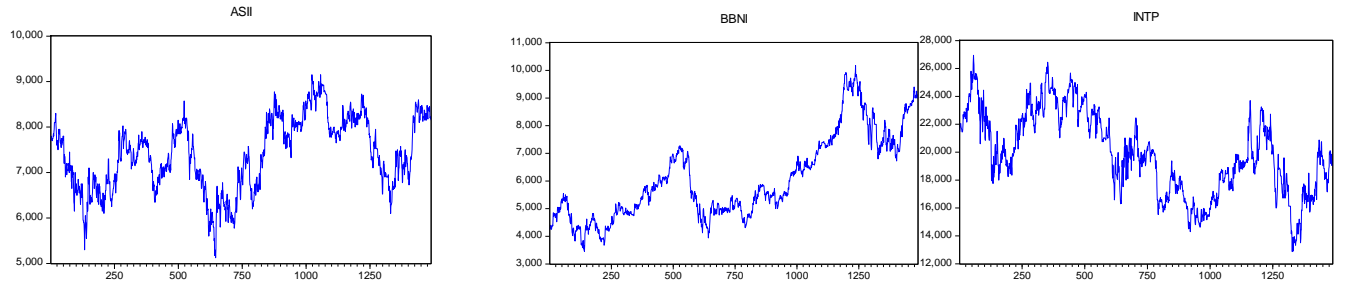

Gambar 1. Plot Runtun Waktu Harga Penutupan Saham ASII, BBNI, dan INTP

Terlihat pada Gambar 1 bahwa ketiga saham mengalami fluktuasi. Hal ini memungkinkan meningkatnya harga ketiga saham pada periode selanjutnya. Berikut merupakan plot return saham ASII, BBNI, dan INTP yang mengalami fluktuasi dari waktu ke waktu yang terdapat pada Gambar 2.
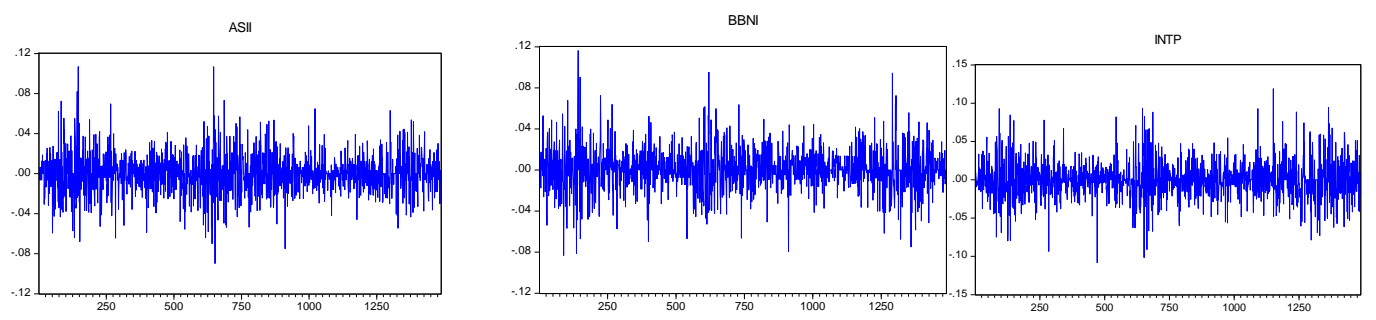

Gambar 2. Plot Runtun Waktu Return Saham ASII, BBNI, dan INTP

Gambar 2 menunjukkan plot runtun waktu return saham ASII, BBNI, dan INTP. Pada periode ini dapat dilihat bahwa adanya volatility clustering yaitu suatu kejadian ketika volatilitas yang tinggi pada suatu periode maka akan terjadi siklis pada periode selanjutnya begitu sebaliknya. Hal ini sering disebut kasus heteroskedastisitas dan dapat diselesaikan dengan menggunakan model ARCH/GARCH. 
Data return masing-masing saham dianalisis menggunakan statistika deskriptif untuk mengetahui gambaran umum data return. Berikut merupakan hasil dari analisis statistik deskriptif dari saham ASII, BBNI, dan INTP pada Tabel 1.

Tabel 1. Statistika Deskriptif Return Saham ASII, BBNI, dan INTP

\begin{tabular}{|l|c|c|c|}
\hline \multicolumn{1}{|c|}{ Variabel } & ASII & BBNI & INTP \\
\hline Mean & $3.82 \mathrm{E}-05$ & 0.000502 & $-8.15 \mathrm{E}-05$ \\
\hline Standar Deviasi & 0.020027 & 0.020366 & 0.024407 \\
\hline Maksimum & 0.106972 & 0.116260 & 0.118928 \\
\hline Minimum & -0.089729 & -0.083150 & -0.108271 \\
\hline Skewness & 0.175391 & 0.120603 & 0.204968 \\
\hline Kurtosis & 5.241170 & 5.654038 & 5.234286 \\
\hline
\end{tabular}

\subsection{Identifikasi Model ARIMA}

Secara visual, plot time series saham dapat dilihat bahwa data return saham telah stasioner dalam mean, dan dari nilai tranformasi Box-Cox diperoleh hasil bahwa return saham stasioner dalam varian. Selanjutnya dilakukan uji secara formal menggunakan uji Augmented Dickey Fuller diperoleh hasil bahwa return saham stasioner atau tidak terdapat akar unit. Selanjutnya pendugaan model ARIMA melalui plot ACF dan PACF dari data return diperoleh model sementara untuk return saham ASII adalah ARIMA ([2,3,4],0,0), ARIMA (0,0,[2,3]), ARIMA ([2,4],0,[3]), dan ARIMA ([4],0,[2,3]). Untuk return saham BBNI adalah $([1,3], 0,0)$, ARIMA $(0,0,[1,3])$, ARIMA ([1],0,[3]), dan ARIMA ([3],0,[1]). Serta untuk return saham INTP adalah ARIMA ([2,4],0,0), ARIMA (0,0,[2,4]), ARIMA ([2],0,[4]), dan ARIMA ([4],0,[2]). Setelah dilakukan uji signifikansi parameter menunjukkan bahwa semua parameter model return saham ASII, BBNI, dan INTP signifikan.

\subsection{Verifikasi Model}

\section{Uji Independensi Residual}

Menggunakan metode Ljung-Box untuk mengidentifikasi apakah residual model berkorelasi atau tidak, diperoleh hasil bahwa dengan tingkat kepercayaan 5\% model dugaan return saham ASII,BBNI, dan INTP tidak memiliki korelasi residual antar lag.

\section{Uji Normalitas Residual}

Menggunakan metode Jarque Bera untuk mengetahui apakah residual model berdistribusi normal atau tidak, diperoleh hasil bahwa dengan tingkat kepercayaan $5 \%$ residual pada semua model dugaan return saham ASII,BBNI, dan INTP tidak berdistribusi normal. 


\section{Uji Heteroskedastisitas}

Uji lagrange Multiplier (LM) yang dikenalkan oleh Engle merupakan suatu uji terhadap kehadiran unsur heteroskedasticity. Uji ini digunakan untuk mengecek ada tidaknya efek ARCH/GARCH pada residual model ARIMA, diperoleh hasil bahwa dengan tingkat kepercayaan 5\% semua model terdapat efek ARCH/GARCH dalam residual. Setelah diketahui bahwa terdapat efek heteroskedastisitas pada sisaan dilanjutkan dengan pemodelan ARCH/GARCH.

\subsection{Pemilihan Model Tebaik}

Pemilihan model dugaan ARIMA terbaik dari masing-masing return saham dilakukan dengan menggunakan kriteria AIC dengan mempertimbangkan nilai AIC terkecil. Model terbaik untuk saham ASII yaitu model ARIMA ([4],0,[2,3]), untuk sahaam BBNI yaitu model ARIMA $(0,0,[1,3])$, dan untuk saham INTP yaitu model ARIMA $(0,0,[2,4])$

\subsection{Model GARCH}

Berdasarkan model terbaik yang terpilih maka dilanjutkan dengan uji signifikansi parameter model GARCH $(1,1)$ dengan tingkat kepercayaan 5\% diperoleh hasil bahwa parameter model untuk saham ASII ARIMA ([4],0,[2,3]) $\operatorname{GARCH}(1,1)$, saham BBNI ARIMA $(0,0,[1,3]) \operatorname{GARCH}(1,1)$, dan saham ARIMA $(0,0,[2])$ GARCH(1,1)adalah signifikan

Selanjutnya model yang dihasilkan oleh masing-masing saham adalah sebagai berikut:

1. Untuk saham ASII

$X_{t}=-0,057181 X_{t-4}+a_{t}-0,088495 a_{t-2}-0,084093 a_{t-3}$

$\sigma_{t}^{2}=0,0000069+0,046591 a_{t-1}^{2}+0,936137 \sigma_{t-1}^{2}$

2. Untuk saham BBNI

$$
\begin{aligned}
X_{t} & =a_{t}+0,055512 a_{t-1}-0,065616 a_{t-3} \\
\sigma_{t}^{2} & =0,00000966+0,073455 a_{t-1}^{2}+0,904895 \sigma_{t-1}^{2}
\end{aligned}
$$

3. Untuk saham INTP

$$
\begin{aligned}
& X_{t}=a_{t}-0,070044 a_{t-2} \\
& \sigma_{t}^{2}=0,0000195+0,047853 a_{t-1}^{2}+0,919309 \sigma_{t-1}^{2}
\end{aligned}
$$

\subsection{Perhitungan Value at Risk (VaR)}

Perhitungan VaR dan ES menggunakan ekspansi Cornish-Fisher dari Persamaan (12) dan (15) karena skewness dan kurtosis yang menunjukkan penyimpangan dari normalitas. Tingkat kepercayaan yang digunakan untuk menghitung VaR dan ES sebesar 95\%. Hasil perhitungan VaR dan ES untuk saham ASII, BBNI, dan INTP dapat dilihat pada Tabel 2 dibawah ini: 
Tabel 2.Hasil Perhitungan VaR dan ES

\begin{tabular}{|c|c|c|c|}
\hline Saham & ASII & BBNI & INTP \\
\hline Rata-rata & 0,0000237 & 0,000151 & $-0,00163$ \\
\hline Varians & 0,0002910 & 0,000342 & 0,000619 \\
\hline Standar deviasi & 0,01707 & 0,018493 & 0,024871 \\
\hline Skewness & 0,175391 & 0,120603 & 0,204968 \\
\hline Kurtosis & 5,241170 & 5,654038 & 5,234286 \\
\hline$F^{-1}(5 \%)$ & $-1,64$ & $-1,64$ & $-1,64$ \\
\hline$F_{5 \%, C F}^{-1}$ & $-1,54919$ & $-1,55674$ & $-1,54071$ \\
\hline$V a R_{5 \%}$ & 0,026421 & 0,028638 & 0,39949 \\
\hline$E S_{5 \%}$ & 0,041008 & 0,043785 & 0,062203 \\
\hline
\end{tabular}

Dari Tabel 2. diatas dengan ekspansi Cornish-Fisher menghasilkan nilai yang lebih besar dari kuantil normal baku. Diperoleh nilai VaR dan ES untuk masing-masing saham sebagai berikut:

1. Saham ASII

Nilai VaR saham ASII sebesar 0,026421, artinya apabila dimisalkan untuk saham ASII dilakukan investasi sebesar Rp. 1.000.000dengan tingkat kepercayaan 95\% maksimum kerugian yang bisa terjadi yang ditanggung oleh investor sebesar Rp. 26.421,00 dalam prediksi waktu satu hari. Nilai ES saham ASII sebesar 0,041008, artinya apabila dimisalkan untuk saham ASII dilakukan investasi sebesar Rp. 1.000.000 dengan tingkat kepercayaan 95\% ekspektasi kerugian yang bisa terjadi yang ditanggung oleh investor sebesar Rp. 41.008,00 dalam prediksi waktu satu hari.

2. Saham BBNI

Nilai VaR saham BBNI sebesar 0,028638, artinya apabila dimisalkan untuk saham BBNI dilakukan investasi sebesar Rp. 1.000 .000 dengan tingkat kepercayaan $95 \%$ maksimum kerugian yang bisa terjadi yang ditanggung oleh investor sebesar Rp. 28.638,00 dalam prediksi waktu satu hari. Nilai ES saham BBNI sebesar 0,043785, artinya apabila dimisalkan untuk saham BBNI dilakukan investasi sebesar Rp. 1.000.000 dengan tingkat kepercayaan 95\% ekspektasi kerugian yang bisa terjadi yang ditanggung oleh investor sebesar Rp. 43.785,00 dalam prediksi waktu satu hari.

\section{Saham INTP}

Nilai VaR saham INTP sebesar 0,039949, artinya apabila dimisalkan untuk saham INTP dilakukan investasi sebesar Rp. 1.000.000 dengan tingkat kepercayaan 95\% maksimum kerugian yang bisa terjadi yang ditanggung oleh investor sebesar Rp. 39.949,00 dalam prediksi waktu satu hari. Nilai ES saham INTP sebesar 0,062203, artinya apabila dimisalkan untuk saham INTP dilakukan investasi sebesar Rp. 1.000.000 dengan tingkat kepercayaan 95\% ekspektasi kerugian yang bisa terjadi yang ditanggung oleh investor sebesar Rp. 62.203,00 dalam prediksi waktu satu hari. 


\section{KESIMPULAN}

Berdasarkan penerapan Exected Shortfall pada model volatilitas ARIMAGARCH untuk menentukan tingkat risiko menggunakan data return penutupan saham harian PT Astra International Tbk. (ASII), PT Bank Negara Indonesia (Persero) Tbk. (BBNI), dan PT Indocement Tunggal Prakarsa Tbk. (INTP). Dapat disimpulkan bahwa model GARCH $(1,1)$ merupakan model yang digunakan untuk meramalkan volatilitas return saham harian. Saham INTP merupakan saham yang memiliki ekspektasi kerugian tertinggi yaitu sebesar 6,2203\% dibandingkan saham ASII sebesar 4,1008\% dan saham BBNI sebesar 4,3785\%.

\section{DAFTAR PUSTAKA}

Artzner, P., F.Delbaen, Eber, J. M. and Heath, D. 1999. Coherent Measures of Risk. Mathematical Finance. Vol.9, No.3, Hal.203-228.

Darmadji,T. dan Fakhruddin, H. 2001. Pasar Modal di Indonesia Pendekatan Tanya Jawab. Jakarta: Salemba Empat.

Ghozali, I. 2007. Manajemen Risiko Perbankan. Semarang: BPUNDIP.

Makridakis, S., Wheelwright, S. C., and McGee, V. E. 1999. Metode dan Aplikasi Peramalan, Edisi kedua. Andriyanto dan Basith, penerjemah. Jakarta: Erlangga. Terjemahan dari : Foecasting Second Edition.

Tandelilin, E. 2010. Portofolio dan investasi : Teori dan Aplikasi. Yogyakarta: Kanisius.

Tsay, R.S. 2005. Analysis of Financial Time Series. Canada: John Wiiley and Sons, Inc

Wei, W.W.S. 2006. Time Series Analysis, Univariate and Multivariate Methods. Canada: Addison Wesley Publishing Company.

Yamai, Y. and Yoshiba, T. 2002. On the Validity of Value at Risk: Comparative Analysis with Expected Shortfall. Monetary and Economic Studies. Vol.2, Hal.57-86. 